\title{
Despesa pública municipal com saúde em Pernambuco, Brasil, de 2000 a 2007
}

\author{
Municipal public health spending in the state of Pernambuco, \\ Brazil, from 2000 to 2007
}

Antônio Carlos Gomes do Espírito Santo ${ }^{1}$ Virgínia Conceição Nascimento Fernando ${ }^{2}$ Adriana Falangola Benjamin Bezerra ${ }^{1}$

${ }^{1}$ Departamento de Medicina Social, Centro de Ciências da Saúde, Universidade Federal de Pernambuco. Av. Prof Morais Rego s/n - Prédio do CCS/UFPE, Cidade Universitária. 50670-420 Recife PE. ag.santo@yahoo.com.br ${ }^{2}$ Residência Multiprofissional em Saúde Coletiva, Universidade de Pernambuco

\begin{abstract}
In order to assess the impact of macropolitical measures implemented in the latter half of the 1990s on the increase in public spending on health and the possible reduction in allocation inequity, a descriptive, quantitative, cross-sectional study was carried out involving $184 \mathrm{mu}$ nicipalities in the state of Pernambuco, Brazil. Data from the Public Health Budget Information System was used, with the selected indicator being spending on health per inhabitant under the responsibility of the municipality. The correlations of this variable with the municipal Human Development Index, population size and value of the municipal budget per capita were analyzed. It was seen that, although the mean increase in municipal spending on health is $190.76 \%$, the value per capita has remained relatively low - at around $R \$ 183.79$ - which is below the national and macro-regional averages. Both spending on health per capita and growth percentages are distributed irregularly among health regions as well as among municipalities within a single region. In conclusion, there is marked allocation inequity among municipalities with regard to the distribution of public resources for health, despite the macro-political measures adopted to reduce this inequity.
\end{abstract}

Key words Brazilian Unified Health System, Health economics, Health financing, Siops
Resumo Com o objetivo de identificar o impacto produzido pelas medidas de macropolítica postas em prática na segunda metade dos anos noventa no crescimento do valor da despesa pública com saúde e na possivivel redução da desigualdade alocativa, foi realizado um estudo descritivo, transversal, de natureza quantitativa, abrangendo os 184 municípios de Pernambuco. Utilizaram-se dados do Sistema de Informações sobre Orçamentos Públicos em Saúde, elegendo-se como indicador a Despesa com saúde sob a responsabilidade do município por habitante. Foi analisada a correlação desta variável com o Índice Desenvolvimento $\mathrm{Hu}$ mana municipal, o porte populacional e o valor do orçamento municipal per capita. Ficou demonstrado que embora o crescimento percentual dos gastos municipais com saúde seja em média de 190,76\%, os valores per capita ainda se mostram bastante reduzidos situando-se em torno de $R \$ 183,79$, bem abaixo das médias nacional e macrorregional. Tanto a despesa per capita com saúde quanto seus percentuais de crescimento distribuem-se de forma bastante irregular entre as regiões de saúde e entre os municípios de uma mesma região. Conclui-se que existe profunda desigualdade entre os municípios na distribuição dos recursos públicos para a saúde, a despeito das medidas de macropolitica adotadas com vistas a sua redução.

Palavras-chave SUS, Economia da saúde, Financiamento em saúde, Siops 


\section{Introdução}

\section{Contextualização do estudo}

No momento em que completa vinte anos, o Sistema Único de Saúde ainda apresenta dificuldades para garantir recursos estáveis e suficientes para o seu financiamento. Ao longo deste período, alternaram-se fontes de receitas, impostos e contribuições sociais, sem que se tenha conseguido ampliar a participação do gasto público com saúde no Produto Interno Bruto ou na receita tributária da União. Isso ocorre em flagrante descompasso com as responsabilidades impostas pela universalização do sistema e seu reflexo sobre o gasto público em Saúde.

Os problemas estruturais observados no sistema público de saúde estão de uma maneira ou de outra, ligados à questão do financiamento. Assuntos como financiamento e gasto com saúde, vêm fazendo parte da preocupação de grupos de estudos, com uma frequência semelhante, talvez, aos temas relacionados com os princípios doutrinários e operativos do Sistema Único da Saúde. As mudanças ocorridas ao longo do contínuo processo de construção do SUS, decorrentes de fatos políticos e econômicos, como também das práticas de gestão da saúde, produziram além das ênfases nesses assuntos, o direcionamento de investigações para essa área de conhecimento ${ }^{2}$.

Este artigo busca contribuir para o desenvolvimento de uma postura essencial ao gestor que é a de localizar, tomar conhecimento, fazer a leitura crítica e utilizar as bases de dados capazes de aportar informação estratégica para boas práticas de gestão. A tentativa de iluminar este objeto de estudo está diretamente relacionada ao esforço para produzir conhecimento numa área de interesse estratégico para a efetivação dos princípios e diretrizes do sistema e que é ainda tão pouco conhecida dos gestores.

\section{Considerações acerca da situação problema e do objetivo}

A maior parte dos estudos relacionados aos gastos em saúde no Brasil aborda a questão utilizando dados agregados para o país como um todo ou, no limite, fazendo comparações macrorregionais, a exemplo do que foi realizado por Santo e Tanaka ${ }^{2}$, com municípios paulistas de grande porte populacional, comprovando que apesar do aumento identificado na despesa com saúde em todos os municípios ao longo do perío- do estudado (2000-2006), esta ainda se acha aquém dos valores praticados em países com padrões elevados de saúde.

Admitindo-se a flagrante heterogeneidade, em todos os aspectos, presente no território brasileiro, cumpre desagregar estes dados a um nível que permita compreender melhor a dimensão desta carência no nível dos estados e municípios, apreendendo o movimento evolutivo deste fenômeno.

Compreender as questões do financiamento envolvidas na determinação das despesas públicas municipais em saúde torna possível aos gestores, profissionais e usuários do SUS uma participação consciente no controle social, indispensável para consolidação do sistema.

Ocorreram significativas mudanças positivas no mecanismo de repasse de receita da União para os municípios, a partir de uma sequência de medidas que tiveram início com a promulgação da Norma Operacional Básica de 1996 (NOB 96), que buscou a responsabilização do poder municipal e a construção de uma rede regionalizada e hierarquizada de serviços (NOB/96, 1997), através da inovação do Piso de Atenção Básica, uma forma de "pré-pagamento", com o estabelecimento de valores per capita mínimos para a totalidade de municípios ${ }^{3}$.

Para Souza ${ }^{4}$ esta mudança formatou um modelo de atenção mais abrangente, avançando assim no processo de redução das diferenças macrorregionais em termos de distribuição de recursos.

A Emenda Constitucional 29, promulgada em 2000, estabeleceu a definição de pisos de distribuição de recursos dos municípios para o SUS, produzindo com isso um incremento da base financeira nas diferentes esferas governativas do sistema de saúde. Os primeiros efeitos positivos já foram sentidos em 2001, contabilizando-se aumento de $10 \%$ no gasto da União com saúde, em relação ao ano anterior. Mesmo assim, alguns entraves persistem, como é o caso do endividamento dos entes subnacionais, gerando dificuldades financeiras para o cumprimento dos percentuais a serem aplicados em saúde estabelecidos pela Emenda, identificando-se ainda dificuldade na aplicação da resolução 322/2003 do Conselho Nacional de Saúde, a qual estabelece as ações e serviços públicos em saúde que podem ser financiados com recursos públicos ${ }^{5,6}$.

É preciso também admitir a lacuna existente no conhecimento acerca dos impactos produzidos por estas mudanças, principalmente no nível da gestão locorregional, haja vista as diferen- 
ças existentes entre estados e municípios referentes a aspectos como capacidade orçamentária, nível de desenvolvimento socioeconômico, estrutura de gestão e porte assistencial.

Este artigo tem como objetivos:

1. Traçar uma análise comparativa entre a evolução da despesa pública municipal com saúde por habitante de Pernambuco, com aquela apresentada pelo Brasil e pela Macrorregião Nordeste, no período de 2000 a 2007.

2. Identificar os diferenciais existentes entre os valores apresentados pelos municípios integrantes da amostra, no que diz respeito à receita e à despesa pública com saúde por habitante, à participação dos recursos próprios do município no custeio desta despesa e à distribuição proporcional dos recursos pelos grandes itens de despesa.

3. Testar o grau de associação entre o porte populacional, o índice de desenvolvimento humano (IDH) e o orçamento municipal per capita com as variações do valor da despesa pública municipal com saúde por habitante dos municípios (DPSH-M) encontrada.

\section{Sobre a fonte de dados utilizada}

O investimento feito em Sistemas de Informações de Saúde no Brasil permite hoje o acesso rápido a dados de interesse em saúde e a elaboração, com relativa simplificação, de estudos de monitoramento e avaliação, ainda que a regularidade no envio e a qualidade dos dados que abastecem aqueles sistemas ainda careçam de melhoria.

Nos processos de tomada de decisão a informação é uma base indispensável, visto que contribui para tornar transparente a relação entre Estado e sociedade civil ${ }^{7}$. O desafio é superar a compreensão da informação como elemento meramente técnico e passar a tratá-la como recurso estratégico, capaz de contribuir no processo de gestão ${ }^{8}$.

O acesso à informação pode potencializar, ainda, a interação pretendida nos processos participativos. É apenas por meio dos fluxos de informações que se possibilita o diálogo, a interpretação dos problemas, limitações e demandas das partes envolvidas na gestão. Além disso, um sistema permanente de informações, que faça uso de todos os meios disponiveis, tem o objetivo de sensibilizar e motivar os indivíduos, que passam a cooperar, desenvolvendo práticas inovadoras e soluções objetivas de atuação conjunta, potencializando, via comunicação e diálogo, o processo decisório e o exercício de controle da gestão pública $[. . .]^{7}$.
Em se tratando de financiamento e gasto, destacamos o Sistema de Informações sobre Orçamentos Públicos em Saúde - Siops como um sistema que tem se firmado desde a sua criação como instrumento de fundamental importância para o acompanhamento das políticas de saúde nas três esferas governativas. Os dados do Siops se mostram relevantes para a elaboração e a implementação de instrumentos de gestão, como é o caso dos Planos Diretores de Regionalização (PDR), os Planos de Investimentos (PDI), os Planos Municipais de Saúde e Relatórios Anuais de Gestão (RAG). Do mesmo modo tem significativa contribuição nos processos de avaliação, tomada de decisão e atendimento às demandas dos órgãos fiscalizadores, a exemplo do Tribunal de Contas e do Ministério Público ${ }^{9}$.

Para o Ministério da Saúde ${ }^{10}$, o Siops "faculta aos Conselhos de Saúde e à sociedade em geral a transparência e a visibilidade sobre a aplicação dos recursos públicos no setor saúde" e deve servir como ferramenta para a gestão no que tange a decisão e negociação no referido setor.

Além disto, desde 2002, em função da parceria entre a Secretaria do Tesouro Nacional (STN) e o Ministério da Saúde, a disponibilização do Demonstrativo da Receita Líquida de Impostos e das Despesas Próprias com Ações e Serviços de Públicos de Saúde (Anexo XVI do Relatório Resumido de Execução Orçamentária) passou a ser produzido automaticamente em decorrência do preenchimento do Siops. Este demonstrativo visa aferir o cumprimento do limite mínimo estabelecido pela EC 29/2000 e segue o disposto na Lei Complemen$\operatorname{tar} n^{\circ} 101$, de 04/05/2000 e nas normas publicadas pela STN, referentes a cada exercício financeiro, sendo preconizado que a periodicidade de publicação do demonstrativo deve ser semestral ${ }^{10}$.

O Siops permite ainda a construção e a aplicação de indicadores que possibilitam avanços no acompanhamento e na avaliação de gastos públicos com a saúde e a realização de um trabalho de análise frente à realidade de alocação de recursos, viabilizando a verificação da adequação do gasto às necessidades da população.

Outras fontes de dados foram utilizadas para a coleta de informações complementares sobre os possíveis determinantes da despesa municipal e se acham descritas posteriormente na metodologia.

Para o gestor da saúde, portanto, utilizar um instrumento como o Siops para embasar suas práticas de planejamento, gestão e avaliação, é uma opção ágil, de baixo custo e de confiabilidade aceitável, critérios fundamentais para a escolha de um sistema de informação. 


\section{Metodologia}

O presente trabalho caracteriza-se como uma pesquisa de natureza quantitativa, descritiva e transversal, uma vez que objetiva observar, descrever e documentar dados, tendo as observações dos fenômenos sob estudo se referido a um único lapso de tempo ${ }^{11}$. O desenho tem por base a agregação de medidas representativas de uma totalidade, enquanto o enfoque priorizado, explicitado nos objetivos, é o da caracterização de uma condição e a sua tradução em valores quantificaveis e passíveis de serem replicados.

O universo é composto pelos 184 municípios de Pernambuco, distribuídos em 11 Gerências Regionais de Saúde (Geres), cujos contornos territoriais correspondem, no Plano Diretor de Regionalização, às microrregiões de saúde. As Geres são escritórios técnico-administrativos da Secretaria Estadual de Saúde, responsáveis pela articulação entre os municípios e pela interlocução deles com a esfera gestora estadual, coordenando os processos de planejamento, execução, acompanhamento e avaliação das ações de saúde, bem como o gerenciamento das unidades públicas de saúde que se acham sob gestão estadual ${ }^{12}$.

A agregação dos municípios por região foi adotada em função de nos estudos quantitativos, com dados secundários, sobre financiamento, a análise dos gastos municipais não dar conta de fenômenos como o da "invasão de demanda", que acontece nos municípios com melhor qualidade de estrutura assistencial, motivado às vezes até pela procura de procedimentos de atenção básica.

Outra questão diretamente relacionada com o financiamento e o gasto em saúde e que requer análises de base locorregional, diz respeito ao mercado de trabalho e à remuneração das equipes da estratégia saúde da família, uma vez que a oferta de salários mais atrativos em um município altera a disponibilidade de profissionais para os municípios vizinhos, e, consequentemente, influencia o fluxo de usuários. O mesmo ocorre em relação à oferta da média e da alta complexidade e as questões decorrentes, como economia de escala, autonomia assistencial e concorrência entre prestadores.

Foram levantados dados relacionados ao indicador de despesa pública municipal com saúde por habitante dos municípios (DPSH-M), no estado de Pernambuco e em suas microrregiões de saúde, no período de 2000 - 2007, disponíveis no Sistema de Informações sobre Orçamentos Públicos em Saúde - Siops. Entenda-se como DPSH-M o recurso empenhado referente à con- trapartida de recursos próprios municipais e às transferências, dividido pelo número de habitantes, indicador denominado pelo Siops como Despesa total com Saúde, sob a responsabilidade do Município, por habitante.

Com base na literatura existente e na observação empírica, foram selecionados como possíveis determinantes do valor da DPSH-M a serem testados, o IDH municipal, o porte populacional do município, o valor do orçamento municipal per capita e o porte assistencial do município sede da Geres.

Os dados foram transferidos para planilhas pré-formatadas no Microsoft Office Excel, 2007, a partir das quais foram construídas as tabelas e gráficos. $\mathrm{Na}$ análise estatística foram empregadas as seguintes medidas: média, desvio-padrão, distribuição por quartis, amplitude de variação e coeficiente de correlação de Pearson.

O estudo apresenta as seguintes variáveis, seus respectivos indicadores e as fontes dos dados:

. Despesa municipal com saúde - Despesa com saúde sob responsabilidade do município per capita; Sítio do Siops.

- Participação das Transferências da União para a saúde na Despesa com Saúde sob Responsabilidade do Município - Percentual de transferências da União para a saúde sobre o total da despesa com saúde sob responsabilidade do município; Sítio do Siops.

. Inserção Locorregional dos Municípios Gerência Regional de Saúde de pertencimento; Plano Diretor de Regionalização de Pernambuco.

. Porte Populacional dos Municípios - Porte populacional; IBGE.

. Porte Assistencial dos Municípios - Porte assistencial; Plano Diretor de Regionalização de Pernambuco.

. Desenvolvimento Humano dos Municípios - Índice de Desenvolvimento Humano (IDH); Programa das Nações Unidas para o Desenvolvimento (PNUD) Brasil.

. Capacidade Orçamentária do Município Valor médio do orçamento per capita; CONDEPE/FIDEM.

\section{Resultados e discussão}

\section{O comportamento da despesa municipal com saúde em Pernambuco}

A DPSH-M média do conjunto dos municípios de Pernambuco mostrou tendência ascendente no período que vai de 2000 a 2007. Trata-se 
de um crescimento real, na medida em que alcança 190,76\%, ultrapassando, portanto, a inflação acumulada no período, que foi de 37,84\%, segundo o Índice Nacional de Preços ao Consumidor - INPC 2 .

Embora se trate de um aumento percentual que supera os valores apresentados, no mesmo intervalo, pelos estados do Sul e Sudeste do país, situa Pernambuco na sexta posição entre os nove estados da Macrorregião Nordeste e o coloca bem abaixo da média de crescimento desta despesa, quando verificada para o Brasil como um todo.

$\mathrm{O}$ incremento observado fez com que Pernambuco atingisse em 2007 uma DPSH-M de R\$ 183,79 , ficando bem abaixo da média nacional, que foi de R\$261,43. Entre os estados da federação, colocou-se naquele ano à frente apenas do Acre e do Amapá (Tabela1).
A Tabela 1 permite ainda identificar que entre os estados nordestinos, os maiores percentuais de crescimento correspondem aos estados que no início da série possuíam os valores mais baixos de DPSH-M e este é o caso da Paraíba, Bahia e Sergipe. Por sua vez, os estados que possuíam os maiores valores de DPSH no ano de 2000 foram aqueles que apresentaram os menores percentuais de crescimento, a saber: Alagoas, Rio Grande do Norte e Maranhão. De qualquer modo, o maior valor de DPSH-M no ano de 2000, pertencente ao estado do Rio Grande do Norte, era quase 3 vezes maior que o menor valor, correspondente à Paraíba. Este desequilíbrio parece ter se reduzido significativamente ao verificar-se que em 2007 o maior valor de DPSH-M, o de Sergipe, foi de 1,38 vezes maior que o menor valor, que coube a Pernambuco.

Tabela 1. Despesa pública com saúde sob responsabilidade dos municípios por habitante, por estados. Brasil, 2000-2007.

\begin{tabular}{|c|c|c|c|c|c|c|c|c|c|c|}
\hline \multirow[b]{2}{*}{ Região } & \multirow[b]{2}{*}{ Estado } & \multicolumn{8}{|c|}{ Despesa com saúde sob responsabilidade dos municípios por habitante } & \multirow{2}{*}{$\begin{array}{c}\text { Crescimento } \\
\text { percentual do } \\
\text { período }\end{array}$} \\
\hline & & 2000 & 2001 & 2002 & 2003 & 2004 & 2005 & 2006 & 2007 & \\
\hline \multirow[t]{7}{*}{ Norte } & $\mathrm{RO}$ & 74,44 & 92,89 & 126,14 & 122,35 & 141,05 & 160,97 & 187,75 & 217,9 & $192,72 \%$ \\
\hline & $\mathrm{AC}$ & 35,4 & 45,2 & 70,22 & 78,67 & 101,02 & 115,78 & 135,41 & 165,1 & $366,38 \%$ \\
\hline & $\mathrm{AM}$ & 55,49 & 71,96 & 93,22 & 97,48 & 115,34 & 133,89 & 178,99 & 196,54 & $245,19 \%$ \\
\hline & $\mathrm{RR}$ & 68,07 & 82,74 & 147,69 & 147,35 & 141,4 & 191,72 & 221,86 & 281,55 & $313,62 \%$ \\
\hline & PA & 73,63 & 82,54 & 100,99 & 111,66 & 134,46 & 143,93 & 166,95 & 188,45 & $155,94 \%$ \\
\hline & $\mathrm{AP}$ & 32,34 & 49,83 & 74,16 & 82,07 & 96,00 & 105,17 & 126,96 & 167,4 & $417,63 \%$ \\
\hline & TO & 82,21 & 93,76 & 122,46 & 128,39 & 160,77 & 187,29 & 225,70 & 272,06 & $230,93 \%$ \\
\hline \multirow[t]{9}{*}{ Nordeste } & MA & 79,93 & 90,28 & 119,73 & 119,3 & 138,77 & 172,50 & 213,81 & 228,12 & $185,40 \%$ \\
\hline & PI & 74,73 & 91,16 & 125,53 & 120,48 & 152,84 & 177,69 & 201,82 & 227,73 & $204,74 \%$ \\
\hline & $\mathrm{CE}$ & 70,52 & 89,8 & 116,84 & 134,6 & 154,48 & 175,91 & 202,59 & 226,93 & $221,80 \%$ \\
\hline & RN & 86,24 & 104,75 & 133,2 & 137,91 & 171,06 & 196,35 & 218,84 & 245,19 & $184,31 \%$ \\
\hline & $\mathrm{PB}$ & 60,68 & 84,54 & 104,71 & 123,7 & 163,19 & 202,17 & 223,59 & 243,82 & $301,81 \%$ \\
\hline & $\mathrm{PE}$ & 63,21 & 77,6 & 99,26 & 100,37 & 122,32 & 139,58 & 168,47 & 183,79 & $190,76 \%$ \\
\hline & $\mathrm{AL}$ & 80,37 & 98,2 & 123,71 & 128,25 & 149,09 & 171,49 & 191,28 & 222,51 & $176,86 \%$ \\
\hline & SE & 44,34 & 67,08 & 99,67 & 119,46 & 153,72 & 180,99 & 208,04 & 254,34 & $473,61 \%$ \\
\hline & BA & 48,69 & 62,52 & 85,19 & 94,45 & 121,91 & 142,95 & 187,19 & 210,42 & $332,16 \%$ \\
\hline \multirow[t]{4}{*}{ Sudeste } & MG & 109,06 & 124,46 & 145,41 & 159,56 & 185,62 & 216,73 & 252,66 & 286,85 & $163,02 \%$ \\
\hline & ES & 67,42 & 83,77 & 108,18 & 119,53 & 148,7 & 173,31 & 203,31 & 240,64 & $256,93 \%$ \\
\hline & RJ & 120,46 & 131,73 & 192,9 & 201,66 & 220,67 & 214,78 & 236,29 & 284,16 & $135,90 \%$ \\
\hline & SP & 111,59 & 127,02 & 156,26 & 167,97 & 212,36 & 240,35 & 268,22 & 312,23 & $179,80 \%$ \\
\hline \multirow[t]{3}{*}{ Sul } & PR & 100,68 & 115,84 & 138,97 & 155,48 & 182,28 & 203,53 & 231,74 & 261,74 & $159,97 \%$ \\
\hline & SC & 82,13 & 99,42 & 126,27 & 148,5 & 181,79 & 208,93 & 239,38 & 273,63 & $233,17 \%$ \\
\hline & RS & 99,66 & 118,4 & 137,13 & 148,54 & 176,56 & 197 & 224,82 & 255,68 & $156,55 \%$ \\
\hline \multirow{3}{*}{$\begin{array}{c}\text { Centro- } \\
\text { Oeste }\end{array}$} & MS & 109,84 & 127,97 & 157,91 & 183,31 & 225,76 & 257,83 & 306,92 & 366,06 & $233,27 \%$ \\
\hline & MT & 95,47 & 121,11 & 143,95 & 166,99 & 208,38 & 239,6 & 259,48 & 288,13 & $198,67 \%$ \\
\hline & GO & 81,62 & 103,31 & 134,9 & 147,91 & 175,4 & 191,84 & 217,46 & 249,2 & $205,72 \%$ \\
\hline
\end{tabular}


A redução nas desigualdades de alocação de recursos entre estados foi objeto de estudo de Souza $^{4}$, que confirma uma diminuição na diferença entre os per capita das unidades federadas. Isto só foi possível em função do aporte de novos recursos, não tendo significado remanejamento entre estados.

Por outro lado, é importante destacar que na relação entre os indicadores de crescimento percentual e de valor absoluto da DPSH-M, o Rio Grande do Norte, mesmo apresentando um dos percentuais de crescimento mais baixos entre os estados do Nordeste, ocupou o posto de melhor DPSH-M em quase todos os anos do período. Em compensação, a Bahia, com um dos maiores percentuais de crescimento, se manteve com o menor valor em vários anos da série. No caso de Pernambuco, ambos os indicadores se mostraram desfavoráveis.

Deve ser ainda assinalado que estados com porte populacional semelhante, apresentam valores de DPSH-M bem diversos. O Ceará, com uma população estimada para 2007 em 8.185.286 habitantes, apresentou valores de DPSH-M, em todos os anos da série, sempre superiores a Pernambuco, com 8.485.386 habitantes, o que, em princípio, demonstra um maior aporte relativo de recursos sob a responsabilidade do município, alocados na saúde.

Alagoas, Rio Grande do Norte e Maranhão, mesmo com percentuais mais baixos de crescimento, inferiores inclusive àquele apresentado por
Pernambuco, chegaram a 2007 com um valor absoluto de DPSH-M superior.

No cenário nacional se observa uma tendência dos entes subnacionais participando cada vez mais do financiamento do SUS em detrimento da União, que embora em termos percentuais represente a maior participação no orçamento da saúde, vem mostrando uma redução da sua participação na composição do orçamento público da saúde ${ }^{13}$. Segundo dados do Conass, entre 1980 e 1990 a União era responsável por mais de $70 \%$ do gasto público com saúde, caindo em 2004 para $50 \%{ }^{5}$. No caso específico do crescimento da DPSH-M, a mesma tem como contribuinte importante a entrada em vigor da Emenda Constitucional 29.

A Tabela 2 sumariza a heterogeneidade existente entre os agrupamentos de municípios que formam os recortes territoriais das diferentes Geres.

Embora o crescimento percentual das DPSHM de todas as regiões de saúde ultrapasse 100\% e a maioria se coloque à frente do percentual médio do estado, tal crescimento se mostra bastante desigual entre elas, oscilando entre os valores extremos de $119,00 \%$, na Geres VII e de 234,39\% na Geres I.

No grupo das Geres que apresentam maiores percentuais de crescimento encontram-se regiões de saúde que estavam entre as menores DPSH-M no começo da série, como é o caso da

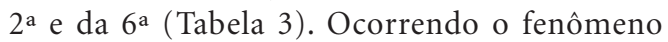

Tabela 2. Dados sócio demográficos e assistenciais das Gerências Regionais de Saúde de Pernambuco.

\begin{tabular}{|c|c|c|c|c|c|c|}
\hline $\begin{array}{c}\text { GERES / } \\
\text { Município Sede }\end{array}$ & $\begin{array}{c}\text { Região de } \\
\text { Desenvolvimento }\end{array}$ & Populaçãoo ${ }^{1}$ & $\mathrm{IDH}^{2}$ & $\begin{array}{c}\% \text { do PIB } \\
\text { do Estado }\end{array}$ & $\begin{array}{c}\text { Orçamento } \\
\text { municipal per } \\
\text { capita }(\mathrm{em} \mathrm{R} \$)^{4}\end{array}$ & $\begin{array}{l}\text { Porte assistencial do } \\
\text { município sede }\end{array}$ \\
\hline I- Recife & Metropolitana & 3.895 .916 & 0,783 & 60 & 644,68 & Sede de Macrorregião \\
\hline II- Limoeiro & $\begin{array}{l}\text { Mata Norte e Agreste } \\
\text { Setentrional }\end{array}$ & 832.086 & 0,650 & 6 & 477,04 & Sede de Microrregião \\
\hline III- Palmares & Mata Sul & 537.734 & 0,626 & 7 & 509,35 & Sede de Microrregião \\
\hline IV-Caruaru & Agreste Central & 1.162 .068 & 0,634 & 9 & 440,55 & Sede de Macrorregião \\
\hline V-Garanhus & Agreste Meridional & 500.795 & 0,598 & 4 & 487,45 & Sede de Microrregião \\
\hline VI- Arcoverde & Sertão do Moxotó & 342.414 & 0,705 & 1 & 472,76 & Sede de Microrregião \\
\hline VII- Salgueiro & Sertão Central & 130.701 & 0,670 & 1 & 420,87 & Sede de Microrregião \\
\hline VIII- Petrolina & Sertão do São Francisco & 397.884 & 0,708 & 2 & 447,72 & Sede de Macrorregião \\
\hline IX- Ouricuri & Sertão do Araripe & 315.429 & 0,613 & 2 & 443,33 & Sede de Microrregião \\
\hline $\begin{array}{l}\text { X-Afogados da } \\
\text { Ingazeira }\end{array}$ & Sertão do Pajeú & 175.864 & 0,618 & 2 & 580,62 & Sede de Microrregião \\
\hline XI- Serra Talhada & Sertão do Pajeú & 206.681 & 0,639 & * & 696,12 & Sede de Microrregião \\
\hline
\end{tabular}

${ }^{1}$ IBGE $2006 ;{ }^{2}$ IBGE 2002; ${ }^{3}$ CONDEPE/FIDEM 2000; ${ }^{4}$ SIOPS 2007; * Dado não disponível no período 
inverso com regiões que tinham naquele ano valores mais altos de DPSH-M e esboçaram baixas taxas de crescimento, a exemplo das Geres V e VII. Mas, diferentemente do que se observa na análise do crescimento e dos valores de DPSH dos estados, aqui se detecta a ocorrência de Geres que combinam valores mais elevados tanto nos percentuais de crescimento quanto nos valores da DPSH-M, como é o caso da Geres I e XI, o que significa que mantiveram suas posições ao longo da série e até se distanciaram das demais. Ao contrário, outras como a III e IV mantiveram seus baixos valores de DPSH-M à custa de um crescimento pífio (Tabela 3 ).

Alguns achados merecem destaque, entre eles o fato de que sete das 11 regiões ficaram abaixo do valor médio da DPSH-M do estado, a qual por isso mesmo é forçada para baixo. A DPSHM mais baixa é a da região VII, que é de 147,48, e a maior é a da região XI, com $\mathrm{R} \$ 228,33$, revelando uma desigualdade que não sofreu diferença significativa ao longo da série, considerando que em 2000 o valor mais alto de DPSH-M era 1,33 vezes maior que o valor mais baixo, enquanto que em 2007 este valor situou-se em 1,54. O valor mais alto neste ano ainda acha-se bem abaixo da média nacional, a qual, como se viu, foi de $\mathrm{R} \$ 261,43$, demonstrando que o ritmo de crescimento obtido revela-se insuficiente para aproximar a DPSH$\mathrm{M}$ das regiões de Pernambuco dos valores vigentes na maioria dos estados brasileiros, independentemente das desigualdades inter-regionais que possam eles também apresentarem (Tabela 3).
Outra constatação é a de que os valores de crescimento percentual maiores e menores ocorrem sem concentrar-se territorialmente, uma vez que os regionais de uma mesma área (zona da mata, agreste ou sertão) apresentam resultados díspares. É o caso das Geres VII e XI, ambas formadas por municípios sertanejos e que detêm, respectivamente, o menor e o maior valor de DPSH-M em 2007. Nesta mesma linha, regiões da zona do sertão, tidas pelas próprias condições climáticas como um desafio ao desenvolvimento mais uniforme do estado, apresentam valores de DPSH-M superiores ao da Região Metropolitana do Recife (Geres I) e do avançado pólo de desenvolvimento representado pela região de Caruaru (Geres IV).

De um modo global, a desigualdade nos valores de DPSH entre os municípios de cada região se reduz de forma bastante discreta, quando se leva em consideração a diferença percentual entre a média da DPSH para o estado e o respectivo desvio-padrão nos anos de 2000 e 2007. Esta diferença, em 2007, varia de 16,91\% na região IV a 73,70\% na região XI, denotando a heterogeneidade de situações e a que ponto chega a desigualdade nos valores de DPSH entre municípios de uma mesma região. De qualquer modo, à exceção da região VII, onde a diferença entre os desvios aumentou ao longo do período, em todas as demais houve uma redução, a qual, em alguns casos, é ínfima, como nas regiões I e II e em outros é bastante acentuada, como acontece com a VI e a X (Tabela 4).

Tabela 3. Despesa pública com saúde sob responsabilidade dos municípios por habitante das Gerências Regionais e do estado de Pernanbuco, 2000-2007.

\begin{tabular}{lrrrrrrrr}
\hline \multirow{2}{*}{$\begin{array}{c}\text { Geres/Região de } \\
\text { Desenvolvimento (RD) }\end{array}$} & \multicolumn{6}{c}{ Despesa Pública com saúde em reais per capita } \\
\cline { 2 - 9 } & $\mathbf{2 0 0 0}$ & $\mathbf{2 0 0 1}$ & $\mathbf{2 0 0 2}$ & $\mathbf{2 0 0 3}$ & $\mathbf{2 0 0 4}$ & $\mathbf{2 0 0 5}$ & $\mathbf{2 0 0 6}$ & $\mathbf{2 0 0 7}$ \\
\hline I/Metropolitana & 65,19 & 75,93 & 96,18 & 112,80 & 203,57 & 147,41 & 176,38 & 217,99 \\
II/Mata Norte & 58,80 & 72,53 & 96,53 & 96,60 & 107,54 & 132,32 & 156,34 & 181,36 \\
III/Mata Sul & 62,68 & 75,43 & 104,82 & 98,80 & 107,27 & 137,36 & 168,14 & 178,95 \\
IV/Agreste Setentrional & 60,91 & 75,47 & 91,60 & 98,87 & 112,41 & 132,55 & 156,05 & 169,91 \\
V/Agreste Meridional & 71,23 & 77,93 & 101,53 & 94,51 & 118,12 & 140,99 & 167,83 & 181,39 \\
VI/Sertão & 54,84 & 67,81 & 91,16 & 98,73 & 108,43 & 127,92 & 167,98 & 170,02 \\
VII/Sertão & 67,32 & 89,02 & 159,27 & 110,93 & 124,80 & 151,66 & 166,24 & 147,48 \\
VIII/Sertão & 64,74 & 101,91 & 113,53 & 114,81 & 120,03 & 151,74 & 173,93 & 189,61 \\
IX/Sertão & 56,49 & 68,33 & 79,99 & 92,87 & 105,32 & 134,24 & 157,61 & 168,69 \\
X/Sertão & 64,75 & 83,86 & 88,16 & 97,59 & 117,22 & 148,73 & 194,04 & 204,16 \\
XI/Sertão & 74,73 & 96,46 & 115,99 & 101,57 & 137,50 & 167,43 & 216,30 & 228,33 \\
Pernambuco & 63,21 & 77,6 & 99,26 & 100,37 & 122,32 & 139,58 & 168,47 & 183,79
\end{tabular}

Fonte: elaboração própria 
Tabela 4. Valor da DPSH-M, desvio padrão e distância percentual entre o valor da DPSH-M e o desvio padrão por Geres. Pernambuco, 2000 e 2007.

\begin{tabular}{|c|c|c|c|c|c|c|}
\hline \multirow{2}{*}{$\begin{array}{c}\text { Geres/ } \\
\text { Município Sede }\end{array}$} & \multicolumn{3}{|c|}{ Ano 2000} & \multicolumn{3}{|c|}{ Ano 2007} \\
\hline & $\begin{array}{l}\text { Valor da } \\
\text { DPSH-M }\end{array}$ & $\begin{array}{l}\text { Desvio Padrão } \\
\text { (DP) }\end{array}$ & $\begin{array}{c}\text { Distância } \\
\text { percentual Valor } \\
\text { da DPSH-M/ DP }\end{array}$ & $\begin{array}{l}\text { Valor da } \\
\text { DPSH-M }\end{array}$ & $\begin{array}{c}\text { Desvio Padrão } \\
\text { (DP) }\end{array}$ & $\begin{array}{c}\text { Distância } \\
\text { percentual Valor } \\
\text { da DPSH/ DP }\end{array}$ \\
\hline I/Recife & 65,19 & 37,18 & 57,03 & 217,99 & 121,71 & 55,83 \\
\hline II/Limoeiro & 58,80 & 18,30 & 31,12 & 181,36 & 53,01 & 29,22 \\
\hline III/Palmares & 62,68 & 23,50 & 37,49 & 178,95 & 55,38 & 30,94 \\
\hline IV/Caruaru & 60,91 & 21,15 & 34,72 & 169,91 & 28,74 & 16,91 \\
\hline V/Garanhuns & 71,23 & 26,45 & 37,13 & 181,39 & 47,54 & 26,20 \\
\hline VI/Arcoverde & 54,84 & 29,01 & 52,89 & 170,02 & 52,23 & 30,71 \\
\hline VII/Salgueiro & 67,32 & 26,02 & 38,65 & 147,48 & 72,62 & 49,24 \\
\hline VIII/Petrolina & 64,74 & 19,34 & 29,87 & 189,61 & 32,62 & 17,20 \\
\hline IX/Ouricuri & 56,49 & 31,36 & 55,51 & 168,69 & 66,51 & 39,42 \\
\hline X/Afogados & 64,75 & 27,27 & 42,11 & 204,16 & 48,04 & 23,53 \\
\hline XI/Serra Talhada & 74,73 & 60,83 & 81,39 & 228,33 & 168,29 & 73,70 \\
\hline Pernambuco & 63,21 & 28,27 & 44,72 & 183,79 & 71,38 & 38,83 \\
\hline
\end{tabular}

Fonte: elaboração própria

A partir da distribuição por quartis, verificase que em 2000, a quase totalidade dos municípios do estado se encontrava igualmente distribuída nos dois primeiros quartis, ou seja, nos estratos de DPSH-M mais baixos. A constatação de que a soma dos municípios destes quartis por região se manteve praticamente inalterada em 2007, leva-nos a observar que considerável contingente de municípios deslocou-se do primeiro para o $2^{\circ}$ quartil.

Embora esse tipo de classificação contribua para estabelecer uma medida de posição dos valores da distribuição denotando basicamente sua relação intragrupo, não se pode perder de vista o aumento verificado nos valores absolutos de DPSH-M ao longo do período, ou seja, mais da metade dos municípios que se achavam enquadrados numa faixa de valores de DPSH-M entre $\mathrm{R} \$ 10,9$ e $\mathrm{R} \$ 58,1$, em 2000 , se deslocaram para uma faixa de valores entre $\mathrm{R} \$ 150,00$ e $\mathrm{R} \$ 300,00$, em 2007.

Sendo a composição da DPSH-M formada basicamente pelas transferências da União para os municípios e pelos percentuais de recursos próprios aplicados, por este, na saúde, faz-se necessário compreender o comportamento evolutivo destas fontes.

As transferências da União para o estado caíram no intervalo 2000-2007 quase 20 pontos percentuais, embora continue tendo uma participação importante na despesa com saúde sob res- ponsabilidade do município, visto que ainda representa mais de $40 \%$ da mesma.

A análise por Geres mostra que esta participação das transferências obedece em todas elas ao movimento de queda. Em 2000, o percentual de participação das transferências na despesa média dos municípios agregados por Geres variava de $56,22 \%$, na $7^{\text {a }}$ GERES, a $74,62 \%$, na $6^{a}$ Geres, com uma diferença percentual de 18,4. Em 2007, esta variação foi de $33,29 \%$ de novo na 7 a Geres a $49,2 \%$ na $4^{\text {a }}$ Geres, importando numa diferença percentual de 15,91. Fica demonstrado, portanto, que a queda da participação percentual das transferências em todas as Geres é patente, mas a diferença entre as que dependem mais e as que dependem menos destes recursos quase não se altera.

As Geres com maior percentual de transferências da União na composição da despesa com saúde foi, em 2000, a $6^{a}$, a $8^{a}$ e a $9^{a}$, todas com percentuais acima de $70 \%$. Os menores percentuais correspondem à $2^{\mathrm{a}} \mathrm{e}$ a $7^{\mathrm{a}}$, situadas na casa dos $56 \%$.

Em 2000, a média do percentual do orçamento municipal aplicado em saúde agregada por Geres já ultrapassava aquele previsto pela EC 29 que era de 7\%. Em 2007, apenas a 7a Geres apresenta um percentual inferior a $15 \%$, que a partir de 2004 passa a ser o piso obrigatório. À exceção desta Geres, as demais variam de $17,01 \%$ na $5^{\text {a }}$ Geres a $22,26 \%$ na 8 a. Geres. 
Uma vez que o volume de transferências da União não acompanha o crescimento dos recursos próprios aplicados em saúde pelo município, o crescimento da DPSH mostra-se fortemente associado ao aumento do gasto municipal, que por sua vez, é bastante influenciado pela EC-29. $\mathrm{O}$ valor percentual mínimo recomendado pela emenda está sendo ultrapassado, chegando a algumas Geres a percentuais acima de 20\%. Mesmo assim, o valor absoluto da DPSH-M continua reduzido, significando que o aumento nos orçamentos municipais e do volume das transferências de recursos da União é que pode elevar aquele valor.

Para uma análise das diferenças inter-regionais procurou-se testar o grau de correlação da DPSH-M com o IDH, o orçamento municipal per capita e o porte populacional, variáveis selecionadas como possíveis determinantes do montante de recursos aplicados na saúde.

O estudo demonstrou que das variáveis selecionadas, apenas o orçamento municipal per capita se correlacionou fortemente com a DPSH$\mathrm{M}$, passando esta correlação de moderada $(0,61)$, em 2000, a forte (0,89), em 2007 (Tabela 5).

A fraca correlação com o porte populacional e com o índice de desenvolvimento humano estaria a demonstrar que tais variáveis, per si, não teriam influência significativa no valor da DPSHM. No caso do porte populacional, isto acontece a despeito de parte do volume das transferências da União para os municípios ter por base o número de habitantes.

No caso do índice de desenvolvimento humano, que remonta às condições existentes em 2000, uma dedução possível é a de que o crescimento da despesa com saúde, a partir de então,

Tabela 5. Correlações (Pearson) entre o valor da despesa com saúde sob responsabilidade do município por habitante (DPSH-M), o porte populacional (POP), o índice de desenvolvimento humano (IDH) e o valor do orçamento municipal per capita (ORÇ/HAB). Pernambuco, 2007.

\begin{tabular}{lcccc}
\hline Variáveis & DPSH-M & POP & IDH & ORÇ/HAB \\
\hline DPSH-M & 1 & & & \\
POP & $\mathbf{0 , 2 7}$ & 1 & & \\
IDH & $\mathbf{0 , 0 8}$ & $\mathbf{0 , 5 0}$ & 1 & \\
ORÇ/HAB & $\mathbf{0 , 8 9}$ & $\mathbf{0 , 0 0}$ & $\mathbf{0 , 0 6}$ & 1 \\
\hline
\end{tabular}

Fonte: elaboração própria não se mostrou atrelado ao imperativo de melhorar o valor do indicador.

A resposta para estas questões talvez esteja exatamente na forte correlação da DPSH-M com o orçamento municipal. Primeiro, se o aumento do valor da DPSH-M nos últimos anos se deu muito mais à custa dos recursos próprios municipais, a pequena correlação da DPSH-M com porte populacional é compreensível, pois esta interfere diretamente no aporte de recursos das transferências.

Se por outro lado o IDH apresenta alguma correlação com o porte populacional e são os municípios menores os que apresentam valores de orçamento mais baixo, a equação estaria explicada.

\section{Conclusão}

Em se tratando de uma pesquisa para a qual não se conta com padrões explícitos que permitam ajuizar o valor da DPSH-M, a análise aqui utilizada baseia-se na comparação dos valores médios de despesa municipal com saúde do estado e de suas regiões, com dados nacionais e dos demais estados da Macrorregião Nordeste.

A análise feita do gasto em saúde mostra uma distribuição bastante heterogênea entre os municípios e as regiões do estado. Este achado não representa por si só um indicador de desigualdade social, merecendo em futuros estudos ser analisado à luz das possíveis iniquidades que possam estar com ele relacionadas, uma vez que não foi possível identificar que tal distribuição possui relação com o porte populacional ou com a localização geográfica dos municípios.

A despesa com saúde sob responsabilidade do município em Pernambuco pode ser considerada baixa, o mesmo ocorrendo com o crescimento verificado no período em estudo $(190,76 \%)$, o qual se coloca como um dos mais reduzidos entre os demais estados da Macrorregião Nordeste. Esta realidade aponta para os limites que as medidas tomadas em nível nacional desempenham no financiamento municipal da saúde.

A média estadual, obtida a partir dos valores de despesa dos municípios com o setor saúde, não consegue alcançar a média do Brasil e da macrorregião Nordeste. Sem uma nova redistribuição tributária, uma opção de acréscimo estável de renda que resta aos municípios seria o aumento do volume de transferências a partir da adesão dos municípios aos programas e projetos que recebem 
incentivos federais, ainda que isto implique sempre na necessidade de contrapartidas.

Esta conclusão baseia-se no fato de que, sendo a composição da despesa municipal com saúde formada pelos recursos próprios aplicados na área e pelas transferências, a possibilidade de aumento no seu valor absoluto acha-se na dependência de incremento no aporte de uma dessas fontes, ou mesmo de ambas.

Como os percentuais de aplicação dos recursos próprios se encontram acima dos 15\%, determinado como mínimo pela Emenda Constitucional 29/2000, os valores de DPSH-M a depender desta fonte, parecem ter chegado a um limite, a serem mantidas as atuais médias de orçamento municipal per capita, apresentadas pelas regiões do estado.

De fato, o orçamento municipal revelou-se um determinante fortemente relacionado com o valor da despesa, ao contrário do IDH e do porte populacional.

Outro elemento que favoreceria os orçamentos municipais está relacionado com o desenvolvimento econômico do estado, que vem experimentando nos últimos anos um PIB per capita superior ao da Macrorregião Nordeste, embora se mostre metade do valor nacional ${ }^{14}$. A desigualdade de participação no PIB estadual entre as diversas regiões, como visto, demonstra que um possível efeito do crescimento econômico sobre os orçamentos municipais depende de políticas de desenvolvimento social mais equânime.

No que diz respeito à fonte representada pelas transferências federais, o aumento do volume de recursos está diretamente relacionado com a fixação do percentual de orçamento da União e da Seguridade Social a ser aplicado na saúde, assunto que ocupa hoje o centro dos debates sobre o financiamento do SUS. A contribuição dos atores que participam na gestão locorregional do sistema de saúde, no sentido de efetuar mudanças a este nível, está voltada para a reivindicação organizada por parte dos colegiados de gestão e de controle social de modo a gerar a necessária pressão política capaz de promover avanços no cenário nacional.
A redução observada nas diferenças entre os valores municipais de despesa no período estudado indica uma redução da desigualdade na alocação de recursos, o que está relacionado com o cumprimento da EC-29. Este fenômeno precisa ser analisado com reservas, uma vez que, apesar do efeito favorável verificado, a maioria das médias municipais de DPSH-M encontra-se com baixos valores.

A realização dessa pesquisa aponta para a necessidade de uma monitoração sistemática dos valores de despesa municipal com saúde a nível nacional, o que permitiria o acompanhamento da tendência evolutiva do financiamento e gasto com saúde, bem como a comparação dessa tendência entre os estados e municípios.

Relacionar esta despesa com a oferta de procedimentos e com a evolução dos indicadores de saúde representa outro desdobramento relevante desta pesquisa, o que implica em retomar o trabalho monográfico de Virgínia Conceição Nascimento Fernando ${ }^{15}$, uma das autoras do presente estudo, o qual buscou explorar as possibilidades de integrar as informações de diferentes bancos de dados (linkage) no sentido de promover uma maior direcionalidade da gestão, apoiada na sequência: aporte de recursos - adequação da oferta de serviços - melhoria dos indicadores de saúde.

Outro resultado dessa pesquisa foi o desenvolvimento do projeto de construção de um fator de alocação de recursos federais para os municípios, linha de pesquisa trilhada nos últimos anos pelo Grupo de Pesquisa em Economia Política da Saúde (GPEPS), da Universidade Federal de Pernambuco (UFPE), ao qual pertencem os autores deste $\operatorname{artigo}^{16}$.

Por fim, espera-se que os atores envolvidos na formulação, na execução e no acompanhamento das políticas públicas de saúde passem, com este estudo, a contar com um desenho de pesquisa capaz de mensurar a evolução da despesa pública municipal com saúde, a partir de um recorte regional, baseado em dados disponíveis nos sistemas oficiais de informação. 


\section{Colaboradores}

ACGE Santo orientou a elaboração do projeto, a coleta de dados, a análise dos resultados e participou da redação do artigo; VCN Fernando participou na elaboração do projeto, na coleta de dados, na análise dos resultados e na redação do artigo; AFB Bezerra participou da redação do artigo.

\section{Referências}

1. Dain S. Os vários mundos do financiamento da Saúde no Brasil: uma tentativa de integração. Cien Saude Colet 2007; 12(Supl.):1851-1864.

2. Santo ACGE, Tanaka OY. Financiamento, gasto e oferta de serviços de saúde em grandes centros urbanos de São Paulo. Cien Saude Colet 2008; 16(3): 1875-1885.

3. Levcovitz E, Lima LD, Machado CV. Política de saúde nos anos 90: relações intergovernamentais e o papel das Normas Operacionais Básicas. Cien Saude Colet 2001; 6(2):269-291.

4. Souza RR. Redução das desigualdades regionais na alocação dos recursos federais para a saúde. Cien Saude Colet 2003; 8(2):449-460.

5. Brasil. Conselho Nacional de Secretários de Saúde (CONASS). Coleção Progestores - Para entender a gestão do SUS - Sistema Único de Saúde. V. 1. 1 a ed. Brasília: Conselho Nacional dos Secretários de Saúde (CONASS); 2007.

6. Brasil. Resolução no 322 de 08 de maio de 2003. Aprova diretrizes acerca da aplicação da Emenda Constitucional no 29, de 13 de setembro de 2000. Diário Oficial da União 2003; 08 mai.

7. Mendes R. A emergência e o protagonismo dos sujeitos. In: Botazzo C, Oliveira M A. Atenção básica no Sistema Único de Saúde: abordagem interdisciplinar para os serviços de saúde bucal. São Paulo: Páginas \& Letras Editora e Gráfica; 2008.

8. Branco MAF. Informação e Saúde: uma ciência e suas políticas em uma nova era. Rio de Janeiro: Editora Fiocruz; 2006.

9. Brasil. Ministério da Saúde (MS). Sistema de Informações sobre Orçamentos Públicos em Saúde. Brasília: Ministério da Saúde (MS); 2004.

10. Brasil. Ministério da Saúde (MS). Regionalização solidária e cooperativa: orientações para sua implementação no SUS. Brasília: Ministério da Saúde (MS); 2007.
11. Polit DF, Hungler BP, Beck CT. Fundamentos de pesquisa em enfermagem: métodos, avaliação e utilização. 5a ed. Porto Alegre: Artes Médicas; 2004.

12. Pernambuco. Secretaria de Saúde do Estado. Plano Diretor de Regionalização- PDR. SUS/ PE. Pernambuco, 2006. [acessado 2009 maio 02] Disponível em: http://portal.saude.gov.br/portal/arquivos/pdf/ pdr_completo_pe.pdf

13. Nunes A. A alocação equitativa inter-regional de recursos públicos federais do SUS: a receita própria do município como variável moderadora. Brasília: Ministério da Saúde (MS); 2004.

14. Condepe/Fidem - Agência Estadual de Planejamento e Pesquisas de Pernambuco. Pernambuco; 2009. [site da Internet]. [acessado 2009 maio 02]. Disponível em: <http://www2.condepefidem.pe.gov.br/web/ condepeFidem\#>.

15. Fernando VCN. Despesa pública municipal com saúde, oferta de serviços e indicadores de morbimortalidade em Pernambuco [trabalho]. Recife (PE): Universidade Federal de Pernambuco; 2009.

16. Bezerra, AFB. Relatório de Pesquisa. Alocação eqüitativa de recursos financeiros para a saúde em Pernambuco: uma proposta metodológica. Edital Facepe 09/2008. Pesquisa para o SUS: gestão compartilhada em saúde. PPSUS - Pernambuco. MS/CNPq/ FACEPE/SES.

Artigo apresentado em 05/12/2011

Aprovado em 10/01/2012

Versão final apresentada em 03/02/2011 